\title{
An Inquiry Tool for Stakeholder Concerns of Architectural Viewpoints: a Case Study at a large Financial Service Provider
}

\author{
Henk Koning \\ Rik Bos \\ Sjaak Brinkkemper
}

Department of Information and Computing Sciences

Utrecht University

Technical Report UU-CS-2006-004 www.cs.uu.nl

ISSN: 0924-3275 


\title{
An Inquiry Tool for Stakeholder Concerns of Architectural Viewpoints: a Case Study at a large Financial Service Provider
}

\author{
Henk Koning, Rik Bos, Sjaak Brinkkemper \\ Department of Information and Computing Sciences \\ University of Utrecht, \\ P.O.Box 80.089 \\ 3508 TB Utrecht, the Netherlands \\ \{h.koning, rik, s.brinkkemper\}@cs.uu.nl
}

\begin{abstract}
In this paper we present an inquiry tool to solicit IEEE Std 1471 stakeholder concerns. The tool is a list of interview questions which help an interviewee to express his concerns. We demonstrate the use of this tool in a case study at a Dutch bank, where an architecture documentation practice is evaluated and extended with three IEEE Std 1471 viewpoints to better address the concerns of the stakeholders.
\end{abstract}

\section{Architectural Concerns of Stakeholders}

Architecture is a relatively new branch of study within software engineering. IEEE Std 1471 [IEEE 2000] defines it as "Architecture is the fundamental organization of a system embodied in its components, their relationships to each other and to the environment and the principles guiding its design and evolution". [Van Vliet 2000] places the architecture definition phase in the software life cycle between the requirements engineering and design phases. In this phase the interests and concerns of all stakeholders are taken into account to come to a well-balanced solution. The setup of the documentation of architecture should reflect these concerns.

The organization of this paper is as follows: in the rest of section 1 we give some introductory material and we describe related work. In section 2 we lay out the research setting and we give a description of the interview questions. In section 3 we show a selection of the interview results. In section 4 we draw our conclusions. Section 5 summarizes future work. The appendix contains the list of interview questions. 


\subsection{IEEE Std 1471}

In 2000, the IEEE Standard 1471 [IEEE 2000] proposed a model of an architecture description and its context. It offers a high level conceptual model for architecture descriptions with explicit attention to the concerns of the stakeholders. For defining IEEE Std 1471 views it is important to have a good understanding of the stakeholder concerns.

An architecture description consists of views that are each made according to a viewpoint. See Figure 1 for the conceptual model. Essential concepts for this study are indicated in bold; where no cardinality is indicated it is ' 1 '. According to the conceptual model a stakeholder is represented by his concerns.

A view is "A representation of a whole system from the perspective of a

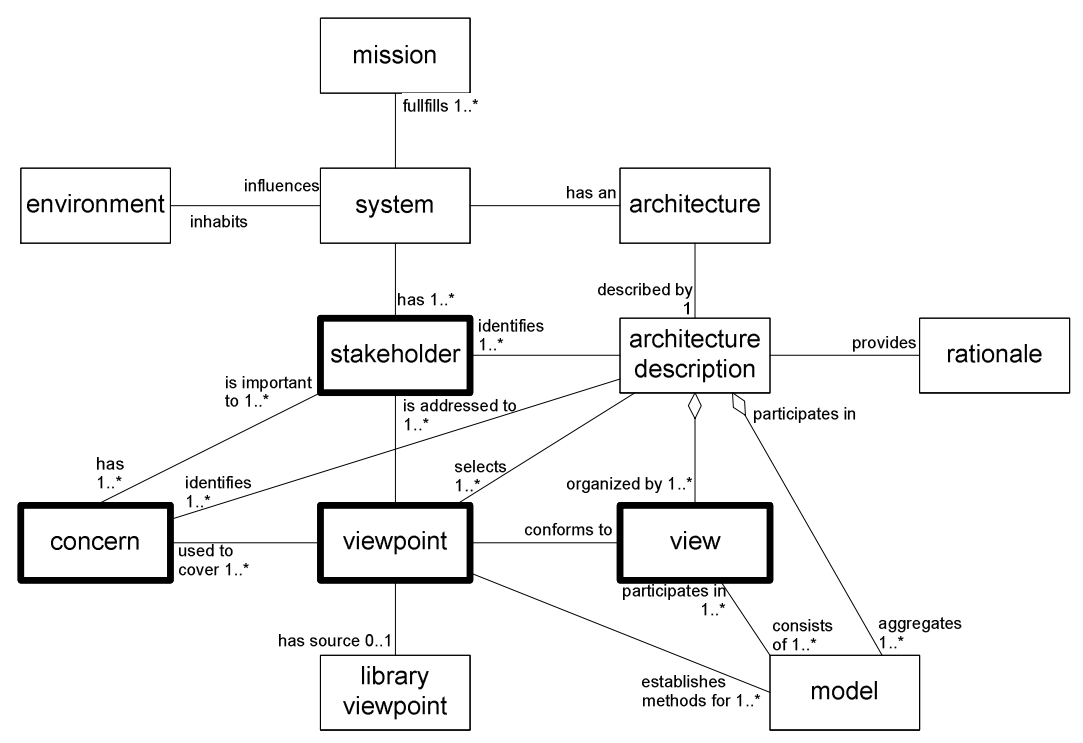

Figure 1. The conceptual model of the IEEE 1471 standard for architectural descriptions

related set of concerns" (p.9), and a viewpoint is "A specification of the conventions for constructing and using a view. A pattern or template from which to develop individual views by establishing the purposes and audience for a view and the techniques for its creation and analysis." (p. 10). A viewpoint can be filed as library viewpoint for later reuse. 


\subsection{Method Viewpoint Design}

In a previous paper [Koning 2006a] we outlined a method for defining IEEE Std 1471 viewpoints. The method presumes that at least an outline of a non-IEEE Std 1471 compliant architecture description is present.

The method has four steps:

1. compile stakeholder profiles (a short table with: goal of the stakeholder, his tasks, his concepts, and his architectural concerns)

2. compile summary of architecture, in text (5 to 10 main statements) and graphics (model of key architectural concepts)

3. relate summary to concerns

4. define viewpoints

In Figure 2 these steps are positioned with respect to the essential concepts of IEEE Std 1471.

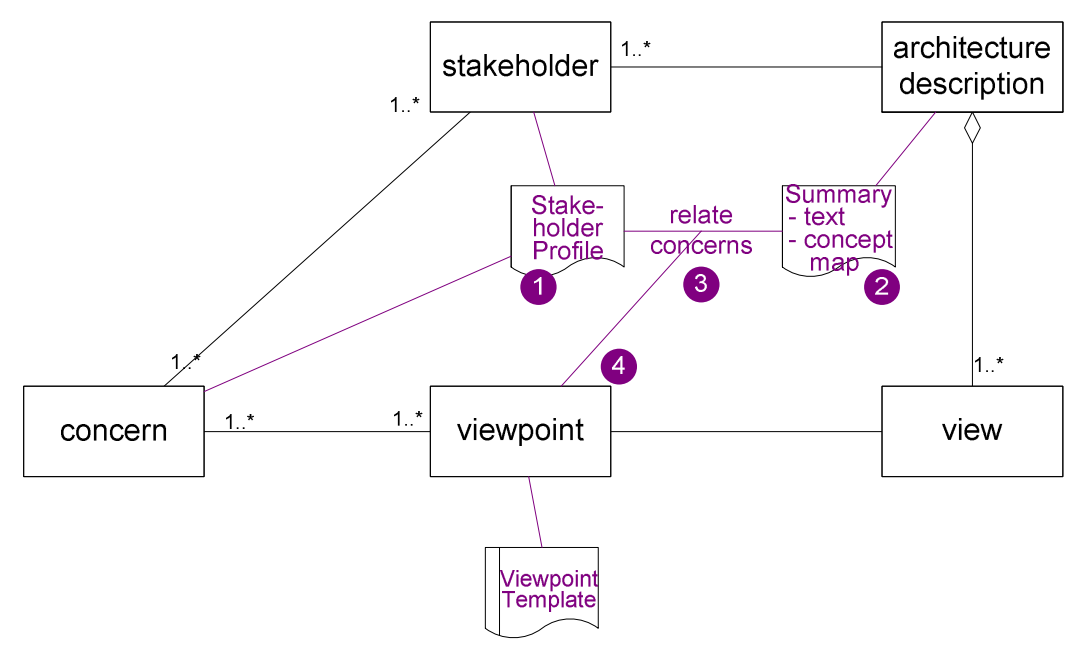

Figure 2. The steps of the method viewpoints design, positioned in IEEE Std 1471

One of the points in the feedback we received on this method was the desire of practicing IT-architects to work from IEEE Std 1471 library viewpoints, instead of creating viewpoints from scratch. In line with our method this means we need to establish concerns of the stakeholders to be able to define the viewpoints, which can be saved as library viewpoints.

\subsection{Related work}

Greefhorst, Koning and Van Vliet [Greefhorst 2004] have created an overview of existing architecture frameworks. One could derive from those frameworks many possible viewpoints to use in documenting IT-architecture. An 
evaluation activity, comparable to the round of interviews discussed in this paper, would be necessary to establish the need for viewpoints.

[Clements 2003] offers many models and guidelines for composing a software architecture description. These models may fit a context for the viewpoints we are interested in.

Smolander and Päivärinta [Smolander 2002] have examined the reasons for making architecture descriptions in practice. Interviews with various stakeholders of architecture in three companies showed that beside the traditional use as a starting point for system design, architecture documents serve to communicate, to negotiate and to capture knowledge. These reasons can be seen as stakeholder concerns.

The elicitation of stakeholder concerns is in our view comparable to the elicitation of requirements for system development for which [Kotonya 1998] has outlined processes and techniques. He advises open interviews, as well as interviews structured by a predefined list of questions.

\section{Research setting}

In this section we lay out the research setting. We first describe our project approach (research method, participating company, interviewees). Then we present stakeholder concerns that were compiled as a prediction. We finally introduce the interview questions.

\subsection{Project approach}

This research project follows an "action research" approach [Baskerville 1999]. In action research five steps are defined: diagnosing, action planning, action taking, evaluation, specifying learning. The evaluation of our method for defining IEEE Std 1471 viewpoints has resulted in learned lessons and has brought us to a new diagnosing activity by means of these interviews. Based on the interviews we will do action planning in the form of proposing new viewpoints.

The action research participants were architecture interested stakeholders working with a company we call FSC in this paper. FSC is a Dutch international bank that attaches great importance to IT architecture to manage its very complex IT operations. With the introduction of FSA (Financial Services Architecture) a major overhaul of all information systems is underway at FSC.

Our contacts at FSC are with an architecture department that maintains a database with information on hundreds of applications (information systems) and their relations. They are often asked to create diagrams of the applications that support a certain business domain. An architecture study, in their case, goes a step further and outlines a 'to be' situation for a business domain. That is to say, which (reduced) set of applications should support the business domain in the future and what software needs to be bought or built. So for this type of reports the concerns are needed. 
The eight architecture interested stakeholders we interviewed were "customers" of the department. Six interviewees were part of the IT department at FSC, in the three roles: manager system development (called Dev1 and Dev2 in this paper), generally interested (GI1 and GI2) and Chief Information Officer (CIO1 and CIO2). Two interviewees were managers from an FSC business department (Biz1 and Biz2). The department considers this a good representation of their customers. Except for CIO1 all interviews were recorded in Dutch, translations in this paper into English are by us.

The department uses a report template of which this is the table of contents:

- Management summary

- Assignment

- Business architecture (organizational structure, functional breakdown, process models, principles)

- Logical IT architecture (ideal positioning in FSA)

- Current Architecture (implementation models, IT solutions)

- Target IT Architecture (future implementation models)

- Migration

We take the table of contents as a starting point for defining viewpoints. Our research question in this paper is: what are, for this department at FSC and their type of documents, the concerns of the stakeholders and what changes in architecture documentation practice are necessitated by these concerns?

\subsection{Forecast}

A forecast was prepared in cooperation with the department. We wanted to be explicit about what we expected and create a reference point for evaluating the outcome of the interviews. See Table 1.

Table 1. Predicted concerns per category of interviewees

\begin{tabular}{ll}
\hline Category & Concerns \\
\hline Dev & Which business requirements do I have to fulfill? \\
& To which architectural guidelines do I have to adhere? \\
GI $\quad$ Does my design fit within the IT architecture? \\
Is there some common ground between this architecture and my \\
interests? \\
If so, how can I react (if necessary)? \\
CIO $\quad$ How to get a minimum number of implementations over the regions? \\
\\
How can I minimize the costs? \\
How can I get more control over the projects? \\
How can I increase the speed of delivery? \\
Do I get the right IT systems for my department(s)? \\
Are the costs of the IT systems not too high? \\
How can I make the most of my opportunities using the IT \\
possibilities? \\
Do I get sufficient service (from IT-department)?
\end{tabular}




\subsection{The interviews}

To make the results of the interviews comparable a detailed list of questions was prepared, see the Appendix.

The list of questions covered five topics:

1. the perception of the interviewee of his own role/function in the company (14 questions).

2. the perception of the interviewee of information technology (17 questions).

3. the ideas of the interviewee on business reports in general (4 questions).

4. the wishes of the interviewee concerning future IT-architecture reports in general (5 questions).

5. the comments of the interviewee on a specific example of an IT-architecture report (10 questions).

Some of the questions in topic 1 ask for attributes of the so called stakeholder profile: 'goal'; tasks; concepts; concerns. This is part of our method for defining IEEE Std 1471 viewpoints.

Section 5 of the interview relates to an existing report. The department chose for this an architecture study of future systems of the domain called Market Risk. This report is representative for the kind of reports they produce.

Question 5.3 'Here is an outline of this reports, could you please indicate for each of your main questions where in the report you find the answer to the question? (this can be done after the interview)' is reminiscent of our research in which we scanned four existing reports for the relation of the content to the concerns of the stakeholders. See [Koning 2004].

\section{Interview results}

The document with the interview questions and all the answers of the interviewed stakeholders spans 47 pages. For the sake of brevity we limit ourselves in this paper to the highlights, in particular to the questions that proved very effective in soliciting concerns: 1.6, 2.12, 4.1 and 5.2. The other questions still provided useful information for the architecture department, for instance about the communication preferences of the stakeholders. A number of questions proved to be not very helpful. We have indicated these in the appendix with a '*' and they will be omitted from a future version of our tool.

We now present a few tables with answers to interview questions. Italics in the answers are by us. After the answers we give a short comment and explain the italics.

\subsection{Concerns - general}

Question 1.6 targets concerns at the level of the function in general of the interviewee. See Table 2.

Table 2. Answers to 1.6: What are your worries? What things did you run after, yesterday? Today? Tomorrow? 


\begin{tabular}{ll}
\hline Interviewee & Answer to interview question \\
\hline Dev1 & Outsourcing / off shoring (to India) \\
& $\begin{array}{l}\text { Successful completion of large scale projects } \\
\text { Too many meetings (too low productivity) }\end{array}$ \\
& Attitude of employees (lot of talk about rights, little attention to \\
plights) & Huge hierarchy, much overhead (too many chiefs, too few indians) \\
Dev2 & Alternative question: what keeps your mind busy? \\
& Answer: direction of the bank with regard to it, what are we going \\
& to do in the coming years? Which systems to use or not; how to \\
& organize the big changes (outdated applications; developers of \\
& age... while technology is changing strongly)(few days training is \\
insufficient, big conceptual changes; motivation? Ability to \\
change?)
\end{tabular}

GI1 Budget wise (for instance medium term planning coming year, safeguard architecture capacity, functional CIO supports from a distance)

Planning wise: little is done with an eye on the long term and that makes it difficult for architectures.

Projects respond to short term and push aside long term goals.

GI2 Having been outsourced, we are divided even further, which makes knowledge being lost.

Difficulty of NL-organization with regard to international financial markets.

Budgets don't coincide.

CIO1 Difficulty of change management, continental Europe not completely ready for the change. Local vision may abide.

Legacy governance, old habits.

$\mathrm{CIO} 2$ Greatest worry is that we have become so big and complex, and yet want to act quickly. The direction of the reorganizations is ok, but the implementation is not manageable (interviewee is responsible for all supporting systems).

Lack of adequate governance and insight in projects portfolio (impact on each other).

The people, busy outsourcing a substantial part of work. $20 \%$ less people in $1 \frac{1}{2}$ year? The work changes from carrying out to directing. There is a low turnover, so a lot of people are older than 40 .

Biz1 (Alternative because of coming end of function: what were your worries?)

Keeping projects in control (scope, goal, end date; will water down if interviewee stops). Prevent friction.

There are so many opportunities that are not seized. One goes on and on in the present ways. Innovation will diminish in the new organization. Functional people are not much IT-minded. Ad hoc 


\begin{tabular}{ll}
\hline Interviewee & Answer to interview question \\
\hline Biz2 & driven. \\
& $\begin{array}{l}\text { See to it that the support functions (Risk management, finance \& } \\
\text { control, operations, IT, HR) understand what the Front Office } \\
\text { needs, worldwide in a uniform way. See to it that priorities are } \\
\text { understood. This means a lot of communicating. } \\
\text { Tomorrow: see to it that it-solutions are aligned and fully } \\
\text { leveraged in line with FO requirements. }\end{array}$ \\
\hline
\end{tabular}

All stakeholders summed up a small list of worries. Some of the worries can be met by a good working architecture department. Architecture gives vision, enables change, etc. We have indicated these with italics. Quite a few stakeholders mention people problems (Dev1, CIO1, CIO2): wrong attitude, inability to change, lack of vision, job losses, and lack of understanding.

\subsection{Concerns - IT}

Question 2.12 asks for the weak points in IT. Indirectly it inquires for the ITconcerns in general of the interviewee. See Table 3.

Table 3. Answers to 2.12: What do you see as the weak points of the way information technology is used in your company?

\begin{tabular}{|c|c|}
\hline Interviewee & Answer to interview question \\
\hline \multirow[t]{2}{*}{ Dev1 } & Too much internal focus, \\
\hline & Bureaucratic/ paper-work (few functions automated) \\
\hline \multirow[t]{2}{*}{ Dev2 } & $\begin{array}{l}\text { We drag along a lot of history, cumbersome to get rid off (technical } \\
\text { and organizational (users and it-persons)) }\end{array}$ \\
\hline & $\begin{array}{l}\text { What - how discussion: distinction sometimes difficult, sometimes } \\
\text { unwanted. End users want specific IT-solution which leads to } \\
\text { stalemate. }\end{array}$ \\
\hline GI1 & $\begin{array}{l}\text { Seen from the business: they use IT as a short term resource. This } \\
\text { leads to ad-hoc solutions which are not so beautiful and with which } \\
\text { you will not reach the long term goals. }\end{array}$ \\
\hline \multirow[t]{2}{*}{ GI2 } & Complexity (applications). \\
\hline & Infrastructure is at places outdated. \\
\hline CIO1 & $\begin{array}{l}\text { We have too much legacy, ergo invested too much. We moved not } \\
\text { quickly enough to new systems, new platforms. So we have too } \\
\text { much ad hoc (bespoke) development. }\end{array}$ \\
\hline \multirow[t]{2}{*}{$\mathrm{CIO} 2$} & Too much diversity. \\
\hline & $\begin{array}{l}\text { Tension between project interests from business vs. architecture } \\
\text { interests. Each time again negotiating. }\end{array}$ \\
\hline Biz1 & $\begin{array}{l}\text { Unfounded trust (too easily it is assumed that things will go right). } \\
\text { Vulnerability, unpredictability. }\end{array}$ \\
\hline Biz2 & $\begin{array}{l}\text { One time } 60 \text { different labels in the market, each own IT } \\
\text { infrastructure. }\end{array}$ \\
\hline
\end{tabular}


From this we determine two interesting concerns. First, there is three times a concern uttered regarding tension with the business, see the italics. The second one that stands out is the big amount of legacy systems / too much diversity (Dev2, CIO1, CO2, Biz2). The department is already aware of this last concern and addressing it in their publications by proposing reductions of the number of systems.

\subsection{Concerns - architecture}

Question 4.1 asks the concerns for IT-architecture in general, see Table 4.

Table 4. Answers to 4.1: Suppose one of these days a new project is launched and an architecture study is started to lay the foundation. What questions would you like to see answered by the study?

\begin{tabular}{|c|c|}
\hline Interviewee & Answer to interview question \\
\hline Dev1 & $\begin{array}{l}\text { Necessity of change. Goal, scope, project results, project } \\
\text { organization and composition (structure project organization), way } \\
\text { of doing, time lines, risks, costs/benefits, principal solution. }\end{array}$ \\
\hline \multirow[t]{2}{*}{ Dev2 } & $\begin{array}{l}\text { Demarcation of domain: which enterprise functions, which } \\
\text { applications. }\end{array}$ \\
\hline & $\begin{array}{l}\text { What often is missing: being conscious of how you come to a } \\
\text { choice, what makes an architecture less good or bad? For instance } \\
\text { "application must be used for all products" (is often not possible, } \\
\text { remains unnoticed). How big is a system allowed to be? For how } \\
\text { many products/systems? Which parameters form the boundaries? }\end{array}$ \\
\hline \multirow[t]{6}{*}{ GI1 } & What is it about? \\
\hline & Which information plays a role, and from which domains? \\
\hline & $\begin{array}{l}\text { How do I expect the applications to look (which functions are in } \\
\text { it)? }\end{array}$ \\
\hline & What is in it and what is the consistency with the environment? \\
\hline & \\
\hline & eted infrastructure? \\
\hline GI2 & $\begin{array}{l}\text { How does it connect to the group architecture (standards)? Does it } \\
\text { indeed connect? }\end{array}$ \\
\hline CIO1 & $\begin{array}{l}\text { Simply: description of business requirements }+ \text { high level how is } \\
\text { the business need resolved }+ \text { how does it fit in the rest of the } \\
\text { architectures. }\end{array}$ \\
\hline $\mathrm{CIO} 2$ & $\begin{array}{l}\text { New project, first question: what is the area you are touching } \\
\text { (current destination plan), do I have common interests, are there } \\
\text { other projects in that area, what is the impact? }\end{array}$ \\
\hline & $\begin{array}{l}\text { (an architecture report goes from business to system plan \& } \\
\text { infrastructure) }\end{array}$ \\
\hline Biz1 & $\begin{array}{l}\text { Where does that change touch me, what is the impact? Red and } \\
\text { green colors ... }\end{array}$ \\
\hline & $\begin{array}{l}\text { Is it complete? Is everything covered? For instance, are all } \\
\text { applications mentioned? }\end{array}$ \\
\hline Biz2 & To what degree support the current applications the business \\
\hline
\end{tabular}




\begin{tabular}{ll}
\hline Interviewee & Answer to interview question \\
\hline processes? \\
Which resources are there for support and which connect in the best \\
way?
\end{tabular}

Various answers, but on the whole they are very supportive of the current architecture model of the department. Some extra concerns identified are: infrastructure, time lines, cost/benefit, relation to other architectures and other projects, see italics. As we will see, time and money are a recurring theme.

\subsection{Concerns - specific report}

Question 5.2 asks for concerns at the level of one specific report, see Table 5.

Table 5. Answers to 5.2: Suppose you would receive this report today for the first time, for which questions would you seek answer when you would start reading?

\begin{tabular}{ll}
\hline Interviewee & Answer to interview question \\
\hline Dev1 & What is the necessity of change? \\
& Who did collaborate? \\
& How will the migration go, and what are the consecutive steps? \\
& I miss the context. \\
& 67 slides is very much; slides with too many words \\
Wish: first essence, main principles; details in appendices. \\
Who has asked for it? \\
Who will decide over the recommendations? \\
Which choices have been made? \\
Why did I receive it? \\
What are the consequences for my domains? \\
Does it fit in my idea of market risk? \\
Why did you send it? \\
With what goal? \\
How does it connect to the group architecture (standards)? Does it \\
connect indeed? \\
How is the business operating? How does it want to operate? How \\
will the needs be solved. \\
This is a catch-up document. \\
What are the subject and the scope? Position in the destination \\
plan. \\
What will the migration look like (80\% costs)? \\
What does it mean in time and labor and can we cope with that? \\
(See it today for the first time) \\
What is it about? Can I find quickly what the intention is? \\
clear right away ...) \\
\end{tabular}




\begin{tabular}{ll}
\hline Interviewee & Answer to interview question \\
\hline & Is it still valid? ....... is quite old. \\
Are the sticking points of the current situation described? & Which principal solution is being proposed? \\
Biz2 & $\begin{array}{l}\text { Can I deduce from the report whether the Market Risk supporting } \\
\text { systems give good support to the Front Office (where the risk has } \\
\text { to be managed)? } \\
\text { What do we have today and in which direction are we heading? }\end{array}$ \\
\hline
\end{tabular}

What strikes us is that there are quite a lot very down to earth questions: why read it? Who has commissioned it? What is it about? The remaining questions are architectural and are covered by the present document setup, so this is affirmative for the work of the department. Only not covered is the question 'What does it mean in time and labor and can we cope with that?' (CIO2).

\subsection{Some miscellaneous questions}

In this section we want to shortly mention a few questions that have not delivered many concerns, but which did gave us pointers for our conclusions.

1.5. What are the 'things' that make up the content of your work? Examples: money, employees, products, ...

Two subjects were mentioned six times: people and money. Meetings were mentioned four times, and information systems and architecture documentation three. Other things were mentioned once or twice.

\section{7: What are the 'things' IT-architecture reports should deal with?}

Question 2.7 asks for the interviewee's grasp of essential architectural concepts, which is connected to the stakeholder concepts of the stakeholder profile (attribute 3). The topics mentioned by the stakeholders in answer to this question are very much in line with the architecture definition of the department, as shown by the existing report. So this is also affirmative of the work of the department. Not in line was one utterance 'The costs, time aspects, capacity aspects.'

\subsection{What is your definition of a failed IT-project?}

The interviewees gave a unanimous response. A failed project runs out of time or money, or it delivers no agreed functional results. This stresses again the importance of time and money in the company culture of FSC.

3.2. Is there a business report that you see as a bad example, that shows a way of communicating that should be avoided? If so, for what reasons?

Most stakeholders used this question to utter wishes for good reports. One of the wishes is: provide cost/benefit analysis. 


\section{Discussion and Concluding Remarks}

In the context of the architecture department of FSC our research questions are: what are the concerns of the stakeholders and what changes in architecture documentation practice are necessitated by these concerns? In chapter 3 the concerns of the stakeholders are exposed, as found by means of the interviews. In this chapter we discuss changes in the documentation practice and some other findings.

Our main conclusion is that the present setup of an architecture report addresses most concerns the stakeholders have for this kind of reports, but that additional viewpoints are necessary. The answers of the interviewees were affirmative for the present work of the architecture department. Another finding is that our method viewpoint design needs to be adapted.

The new viewpoints are to cover time aspects, money aspects and people aspects. These aspects show prominent in the answers of the interviewees, but are not covered by the existing architecture document setup of the department.

Time aspects entail questions like when will which parts of the proposed architecture be realised? And how much time is accounted for in the migration. Many things are happening at the same time at FSC and proposed activities are not taken seriously when they are not fixed on the calendar somewhere. The department had until now the habit to leave the fixing of dates to the next process after the publication of an architecture study.

Money aspects entail questions like how much do the current operations cost? How much are the costs of the migration? How much will the operations cost after that? One of the big business drivers at FSC at the moment is the reduction of operating costs. For each new activity it is important to know what effect it will have on operating costs. Until now the precise calculation of financial benefits and burdens was left to the system design projects that would follow on the architecture study. It is the intention of the department to finish up architecture reports with financial data with the help of a portfolio manager.

People aspects entail questions like: how much more or less people will work at FSC after the introduction of the proposed architecture? What new skills are demanded of system developers or end users? Will the migration activities be conducted by FSC personnel or will they be outsourced? This is a new area of attention.

The adaptation of our viewpoint design method entails the extension of step 1 (compile stakeholder profiles) with an activity to perform a stakeholder interview, based on the interview questions in the Appendix. The big difference between the forecasted concerns and the found concerns makes this a necessary extension.

We found the round of interviews a meaningful exercise and a good way to evaluate the current documentation practice of the department. Some needed additions to the documentation setup were found. 
The list of interview questions functioned well as a 'Stakeholder Concern Inquiry Tool'. Many architectural stakeholder concerns were uncovered and some relevant ingredients of the company culture were brought to our attention. Some questions that did not help in soliciting concerns and did not reveal any other useful evaluation information will be evicted from the list (indicated by a ' $*$ ' in the appendix).

\section{Future work}

We want to turn the list of questions into a standard questionnaire that can be used to evaluate an architecture documentation practice. Some questions that were not so helpful in soliciting stakeholder concerns will be removed from the list. The questionnaire will be made available on-line [Koning 2006b].

We want to see what more can be learned from practices in the area of requirements engineering and apply that to soliciting of stakeholder concerns.

\section{Acknowledgements}

We thank Rich Hilliard and Slinger Jansen for their valuable comments. We thank FSC for giving us the possibility to conduct these interviews.

\section{References}

1. [Baskerville 1999] R.Baskerville, Investigating Information Systems with Action Research, Communications of the Association for Information Systems, 2(19): 1- 31.

2. [Clements 2003] P. Clements, F. Bachman, L. Bass, D. Garlan, J. Ivers, R. Little, R. Nord, J. Stafford, Documenting Software Architectures: Views and Beyond, AddisonWesley, Boston.

3. [Greefhorst 2004] D. Greefhorst, H. Koning, H. van Vliet, The many faces of architectural descriptions, accepted for publication by journal Information Systems Frontiers (vol. 7, no. 3).

4. [IEEE 2000] IEEE, IEEE recommended practice for architecture description, IEEE Standard 1471.

5. [Koning 2004] H. Koning, H. van Vliet, Real-life IT architecture design reports and their relation to IEEE Std 1471 stakeholders and concerns. Accepted for publication by the Automated Software Engineering (ASE) Journal.

6. [Koning 2006a] H. Koning, H. van Vliet, A Method For Defining IEEE Std 1471 Viewpoints. Accepted for publication by the Journal of Systems and Software, volume 79 no 1.

7. [Koning 2006b] Homepage of this research: http://www.cs.uu.nl/people/koningh.

8. [Kotonya 1998] G. Kotonya, I. Sommerville, Requirements Engineering: Processes and Techniques, John Wiley \& Sons

9. [Smolander 2002] K. Smolander, T. Päivärinta, Practical Rationale for Describing Software Architecture, Beyond Programming-in-The-Large, proceedings of 3rd Working IEEE/IFIP Conference on Software Architecture (WICSA3), August 25-30, 2002, Montreal, Québec, Canada, Jan Bosch et.al., ISBN 1-4020-7176-0, page 113125.

10. [Van Vliet 2000] H. van Vliet, Software Engineering: Principles and Practice, John Wiley \& Sons, Chichester. 


\section{Appendix Interview questions Stakeholder Concern Inquiry Tool}

The list of interview questions that were used in the case study treated in the paper. With a '*' are questions marked that will be omitted from future versions of this tool.

\section{Perspective of interviewee on his own role in the company}

1.1. What is the name of your role/function in the company?

1.2. What is the goal of your role/function?

1.3. What are your tasks?

1.4. * Are there tasks that you could perform, but which you consider outside your responsibility?

1.5. What are the 'things' that make up the content of your work? Examples: money, employees, products, ...

1.6. What are your worries? What things did you run after, yesterday? Today? Tomorrow?

1.7. ${ }^{*}$ How do you keep control over your work?

1.8. * What kind of happenings can derail the functioning of your department?

1.9. * How do you take part in the decision taking processes in the company?

1.10. * From which parties do you receive directives for your work?

1.11. * To which parties do you give directives?

1.12. * What are the reporting guidelines to which you must adhere?

1.13. * Do you have salary bonus system, and if so, what are the mechanics of that?

1.14. * What are your plans for the future?

\section{Experiences/expectations/relevancy of strategic IT projects}

2.1. What does IT mean to you?

2.2. * What effect does IT have on your department?

2.3. How would you describe what a 'strategic IT decision' is?

2.4. Can you give some examples of strategic IT decisions?

2.5. * Are you involved in decision taking regarding IT? If so, how?

2.6. What would be your description of IT-architecture?

2.7. What are the 'things' IT-architecture reports should deal with?

2.8. * What is redundant in an IT-architecture?

2.9. In what circumstances is an architecture study needed?

2.10. * In what circumstance is an architecture study superfluous?

2.11. * What do you see as the strong points of the way information technology is used in your company?

2.12. What do you see as the weak points of the way information technology is used in your company?

2.13. What is your definition of a failed IT-project?

2.14. * What is your definition of a successful IT-project?

2.15. In which ways do you receive information about strategic IT-projects?

2.16. What do you like of each way you receive information about strategic ITprojects, what do you dislike, and why?

2.17. Do you have a wish for the way in which you would like to receive information about strategic IT-projects in future?

3. Business reports in general

3.1. * Is there a business report that you would like to be used as an example for 
future reports? If so, for what reasons?

3.2. ${ }^{*}$ Is there a business report that you see as a bad example, that shows a way of communicating that should be avoided? If so, for what reasons?

3.3. * How do you compare written reports on paper to information on intranet webpages or powerpoint slide shows? Advantages/disadvantages? Application?

3.4. *Would you like to have templates used all the time?

4. Wishes future IT-architecture reports

4.1. suppose one of these days a new project is launched and an architecture study is started to lay the foundation. What questions would you like to see answered by the study?

4.2. * What questions should be skipped in an architecture study?

4.3. * If you could fully trust the IT-department, would that change the way you want to be informed?

4.4. At what moments would you like to be involved in the architecture study? For what issues/reasons?

4.5. Wishes with regard to publication media and form?

\section{Opinions/wishes about an example report}

5.1. Can you please give your own description of what this report is about?

5.2. Suppose you would receive this report today for the first time, for which questions would you seek answer when you would start reading?

5.3. * Here is an outline of this reports, could you please indicate for each of your main questions where in the report you find the answer to the question? (this can be done after the interview)

5.4. * Are you missing information in the report to answer your questions?

5.5. * If you had to explain the content of this report to a newcomer, to which section (text or diagram) would you refer?

5.6. ${ }^{*}$ How much time did you spend on reading?

5.7. * How quick could you find the information you needed?

5.8. Do you consider this report good readable? Can you explain?

5.9. Do you have any other comment on the setup of this document? (Please don't comment on the content, but only on the way it is presented.)

5.10. Do you agree or disagree with the report? To what extent? Advantages/benefits? Disadvantages/losses?

\section{Closure}

6.1. What do you think about this interview? Do you think we understand your needs?

6.2. Can you see the relevancy of the topics discussed?

6.3. Did you miss any aspects?

6.4. Do you have any closing remarks? Advice?

6.5. Thank you very much for your cooperation! 